\title{
Optimal Allocation of a Hybrid Photovoltaic Biogas Energy System Using Multi-Objective Feasibility Enhanced Particle Swarm Algorithm
}

\author{
Hussein M. K. Al-Masri ${ }^{1}{ }^{*} \mathbb{D}$, Abed A. Al-Sharqi ${ }^{1}{ }^{\circledR}$, Sharaf K. Magableh ${ }^{1}{ }^{\circledR}$, Ali Q. Al-Shetwi ${ }^{2}$, \\ Maher G. M. Abdolrasol ${ }^{3}$ (D) and Taha Selim Ustun ${ }^{4}$ (D) \\ 1 Department of Electrical Power Engineering, Yarmouk University, Irbid 21163, Jordan; \\ alsharqi619@gmail.com (A.A.A.-S.); sharaf.magableh@outlook.com (S.K.M.) \\ 2 Electrical Engineering Department, Fahad Bin Sultan University, Tabuk 47721, Saudi Arabia; \\ aalshetwi@fbsu.edu.sa \\ 3 Department of Electric, Electronics and System Engineering, Faculty of Engineering and Built Environment, \\ Universiti Kebangsaan Malaysia, Bangi 43600, Malaysia; maher.abdolrasol@gmail.com \\ 4 Fukushima Renewable Energy Institute, AIST (FREA), National Institute of Advanced Industrial Science and \\ Technology (AIST), Koriyama 963-0298, Japan; selim.ustun@aist.go.jp \\ * Correspondence: h.almasri@yu.edu.jo; Tel.: +962-2-7211111 (ext. 4658)
}

Citation: Al-Masri, H.M.K.; Al-Sharqi, A.A.; Magableh, S.K.; Al-Shetwi, A.Q.; Abdolrasol, M.G.M.; Ustun, T.S. Optimal Allocation of a Hybrid Photovoltaic Biogas Energy System Using Multi-Objective Feasibility Enhanced Particle Swarm Algorithm. Sustainability 2022, 14, 685. https://doi.org/10.3390/su14020685

Academic Editors: Md Abdul Alim Md Khairul Alam, Md Imran Hosen and Mohammad Ashraful Alam

Received: 8 November 2021

Accepted: 4 January 2022

Published: 9 January 2022

Publisher's Note: MDPI stays neutral with regard to jurisdictional claims in published maps and institutional affiliations.

Copyright: (C) 2022 by the authors. Licensee MDPI, Basel, Switzerland. This article is an open access article distributed under the terms and conditions of the Creative Commons Attribution (CC BY) license (https:// creativecommons.org/licenses/by/ $4.0 /)$.

\begin{abstract}
This paper aims to investigate a hybrid photovoltaic (PV) biogas on-grid energy system in Al-Ghabawi territory, Amman, Jordan. The system is accomplished by assessing the system's reliability and economic viability. Realistic hourly measurements of solar irradiance, ambient temperature, municipal solid waste, and load demand in 2020 were obtained from Jordanian governmental entities. This helps in investigating the proposed system on a real megawatt-scale retrofitting power system. Three case scenarios were performed: loss of power supply probability (LPSP) with total net present cost (TNPC), LPSP with an annualized cost of the system (ACS), and TNPC with the index of reliability (IR). Pareto frontiers were obtained using multi-objective feasibility enhanced particle swarm optimization (MOFEPSO) algorithm. The system's decision variables were the number of PV panels $\left(N_{p v}\right)$ and the number of biogas plant working hours per day $\left(t_{\text {biogas }}\right)$. Moreover, three non-dominant Pareto frontier solutions are discussed, including reliable, affordable, and best solutions obtained by fuzzy logic. Double-diode (DD) solar PV model was implemented to obtain an accurate sizing of the proposed system. For instance, the best solution of the third case is held at TNPC of 64.504 million USD/yr and IR of $96.048 \%$. These findings were revealed at 33,459 panels and 12.498 h/day. Further, system emissions for each scenario have been tested. Finally, decision makers are invited to adopt to the findings and energy management strategy of this paper to find reliable and cost-effective best solutions.
\end{abstract}

Keywords: photovoltaic; biogas; hybrid systems; double-diode; multi-objective feasibility enhanced particle swarm optimization (MOFEPSO) algorithm

\section{Introduction}

The demand for energy resources has increased dramatically over the last few decades as a result of the industrial revolution and the world's growing population. This leads to a decline in traditional energy reserves such as fossil fuels and natural gas, necessitating the development of alternative resources in order to meet the growing demand on energy [1]. In addition, fossil fuels are the largest sources of carbon dioxide $\left(\mathrm{CO}_{2}\right)$ emissions, which cause the greenhouse phenomenon that leads to climate change [2]. In other words, fossil fuels are considered as non-renewable energy sources that cause both environmental and human health issues. Therefore, such concerns have encouraged researchers and decision makers to find energy resources which are not only alternatives, but also clean, environmentally 
sustainable, and renewable [3]. The best alternatives to fossil fuels are renewable energy (RE) resources. They generate the required power from naturally replenished resources. RE resources are sustainable, affordable, global, environmentally friendly, and reliable energy supplies. This helps in compensating the increasing energy demand, especially on fossil fuel sources, in few decades [4]. RE resources are unlimited as they can be replenished over time. There are different types of RE resources, such as solar and biogas. Solar energy is the energy that comes in the form of heat or light generated energy. Solar photovoltaic (PV) energy can be harvested directly from solar irradiation and transformed into electrical energy using solar PV panels. Accordingly, PV energy could be utilized to satisfy load demands [5]. There are many merits of PV energy that could be noticed for the system presented in this study. It is considered as an affordable resource of energy. This has been judged based on the radiation intensity which determines the potential of solar energy in Jordan [6]. Moreover, PV systems, after installation, are considered as pollution-free energy resources. Moreover, PV systems are considered as reliable, modular, available, and silent energy resources.

On the other hand, biogas is generated from many sources such as biogas plants using biochemical reactions. These reactions involve the use of enzymes produced from anaerobic bacteria throughout the anaerobic digestion process. Moreover, biogas is a mixture of methane (55\% to $65 \%), \mathrm{CO}_{2}(30 \%$ to $40 \%)$, and other gases $\left(\mathrm{H}_{2}, \mathrm{H}_{2} \mathrm{~S}\right.$, and $\left.\mathrm{N}_{2}\right)$ [7]. It is essential to mention that the heating value contained in the biogas is highly dependent on the percentage of methane gas. Indeed, biogas could be used as an input fuel to generate electrical energy using biogas power generator. Due to the high content of $\mathrm{CO}_{2}$ in biogas, it is considered a slow-burning gas process [8-10]. There are five biomass energy conversion technologies which could be used in the conversion into useful energy. These are thermal, thermochemical, biochemical, chemical, and pyrolysis conversion technologies [11,12].

The main drawbacks of some RE resources such as PV and wind are the unpredictable nature and the reliability issue if these resources are used individually. In this context, these resources also depend on the geographical location. In this paper, hybridizing PV energy with biogas energy to produce a Hybrid Renewable Energy System (HRES), could help find a reliable and an affordable renewable resource of energy to some extent. Grid-connected HRES have the primary advantage of utilizing the grid to provide backup energy to the hybrid system in the event of an energy deficit to meet the load demand. This can preclude the need of a storage equipment with bulky size and high capital cost. However, the configuration of the HRES requires an optimal design taking into consideration many economical, technical, environmental, and reliable indicators. Therefore, optimization techniques are essential to find the best design of the hybrid system parameters. This investigation will focus on the optimization of PV-biogas grid-connected system for different combinations in Al-Ghabawi Area, Amman, Jordan. The hybridization of the PV plant with biogas is possible due to Jordan's massive amounts of non-recycled trash that may be used to generate power. As a result, this system is tested, simulated, and optimized using real-time recorded solar irradiance and hourly wastes for the Al-Ghabawi region, Amman, Jordan.

Reviews on the recent studies related to the hybrid PV-biogas system will be highlighted. This is in order to show the novelty of the research presented in this paper. In [13], the authors designed an off-grid HRES consisting of a wind turbine, solar PV, and biogas plant to cover the load demand of a typical house in the United Kingdom using HOMER software. The obtained results reveal that the best solution is met with a $1 \mathrm{~kW}$ wind turbine, $1 \mathrm{~kW}$ biogas plant, $1 \mathrm{~kW}$ power converter, and four batteries. The TNPC of this system is equal to USD 14,507, and the cost of energy (COE) is equal to $0.588 \mathrm{USD} / \mathrm{kWh}$, which helps include the TNPC as an objective function to be minimized in this paper. It is worth mentioning that the other objective function considered in the multi-objective optimization problem is the LPSP. However, this work does not include a detailed mathematical model for each system's component. In [14], the authors employed Artificial Bee Colony (ABC) algorithm and HOMER software to find the optimal design of PV-biomass HRES in on-grid and off-grid configurations. The results indicate that the on-grid system is more reliable and 
more cost-effective than the standalone system. Moreover, the results obtained by the ABC algorithm were found to be more economically feasible than those obtained by HOMER. This can be noticed from the numerical results of the levelized cost of energy (LCOE). The LCOE values for both on-grid and off-grid systems, acquired by HOMER software, are equal to $0.118 \mathrm{USD} / \mathrm{kWh}$ and $0.366 \mathrm{USD} / \mathrm{kWh}$, respectively, whereas the results obtained by ABC algorithm are equal to $0.110 \mathrm{USD} / \mathrm{kWh}$ and $0.360 \mathrm{USD} / \mathrm{kWh}$, respectively. The summarized results of this paper include economic feasibility and reliability issues, but it has been noticed that reliability indices to satisfy the investigated load demand, such as IR and LPSP, have not been considered in the mathematical modeling and the optimization process as well. Thereby, these results inspired this research to select three solutions in the multi-objective optimization results, i.e., reliable, affordable, and the best solution. This enables a fair comparison of the proposed findings in this research.

In [15], the researchers investigated the feasibility of using the pine needles as an input fuel to a biomass gasifier combined with PV and wind renewable energy resources to provide sufficient energy to an on-grid system located in the western Himalayan territory. HOMER software is used to find cost and ecological parameters in three different cases: PV/Biomass/Grid as in case 1, PV/Wind/Biomass/Grid as in case 2, and Grid only as in case 3 . The configuration of the first case was found to be the best scenario with cost of energy (COE) equals $0.102 \mathrm{USD} / \mathrm{kWh}$, which is $29 \%$ lower than COE in case 2 and $7 \%$ lower than COE in case 3. In addition, the TNPC of this configuration equals USD 42,081. Moreover, the contribution of biomass energy resource was $61 \%$, followed by PV with a $22 \%$ share of the total energy generation, while $17 \%$ is coming from the grid connection. On the other hand, the reliability issue has not been taken into consideration in a multiobjective optimization problem. The system could be affordable at a certain solution, but it could fail to supply the load demand at this solution. Finally, the environmental analysis reveals that the investigated system would reduce the $\mathrm{CO}_{2}$ emissions by $27.8 \mathrm{Mt} /$ year compared with diesel systems. Consequently, the reliability and environmental impacts of each system's scenario are considered and evaluated in this study and will be discussed in Sections 3.5 and 3.6, respectively.

In [16], the researchers examined an off-grid hybrid solar PV/wind/biomass/pumphydro-storage system. They optimized the system based on economic, ecological, and technical performance indicators. Their objective was to minimize COE, considering the unit-sizing of the renewables as decision variables. They used three algorithms to extract and validate their results. The algorithms include whale, firefly, and particle swarm optimization algorithms. The constraints of the proposed system were the LPSP and the excess energy fraction. However, the grid-connected system was not investigated. As a matter of fact, the grid-connected system may be more reliable than the standalone configuration. The study outcomes indicate that the investigated system is economically and environmentally feasible. In addition, the COE of the pumped-storage system was $16.63 \%$ lower than using batteries as a storage system. Hence, this inspires this research to add more technical indicators to be computed at each case of the optimized system (i.e., reliable, affordable, and best solutions). For instance, the energy expected not served (EENS) and loss of load probability (LOLP) were computed in each aforesaid case. In [17], the authors investigated the flexibility and scalability of a solar PV/wind/biomass grid-connected system. They determined the system size using the objective function of minimizing the HRES life cycle cost (LCC). Their findings reveal that the best optimal configurations will be obtained when combining the three selected renewables in an on-grid system with a LCC of USD 30 million. However, they did not consider reliability issues while sizing the system. It is important to mention that reliability is a vital concern that must be considered along with the cost. Therefore, in this research, several technical reliability performance indicators were considered. For instance, an optimum solution will be demonstrated in this study which is a compromised solution in terms of system's affordability and reliability.

The authors in [18] presented an advanced sizing technique for a solar PV array integrated with a pumped hydro storage on-grid system. They designed their system 
based on two case scenarios. Firstly, the head losses in the hydropower facility while the recombination loss in the PV output power model have not been considered. These losses have been taken into account in the second scenario. Their objective was to maximize power system reliability whilst meeting the technical designed constraints. The proposed methodology indicates an accurate unit-sizing for the second scenario. The second case has more RE units, but it was more reliable and ecological than the first scenario. Their research inspires us to include the double-diode (DD) solar PV module to obtain the accurate value of PV output power, which in turn will impact the entire system configurations. However, they did not take into consideration any cost effect on the system. In this context, three multi-objective case scenarios were performed in this paper, i.e., TNPC with LPSP, ACS with LPSP, and TNPC with IR. Additionally, other reliability and environmental impacts were computed at each case of the optimal solutions.

In [19], the authors developed a detailed mathematical model for PV-biogas hybrid energy system using the multi-objective grey wolf optimization algorithm (MOGWOA). Three different solutions were selected from the Pareto frontier. In the first two cases, reliable, affordable, and compromised solutions were investigated, while in the third case environmental, affordable, and compromised solutions were performed for the on-grid system case. The results showed that the on-grid system was more reliable and affordable than the off-grid system at the compromised solution. Further, the compromised solution provided an environmentally accepted solution in the case of an on-grid system. They use MOGWOA to find the optimal Pareto frontier and then select the reliable, affordable, and compromised solutions. However, this study did not use an advanced mathematical model for the solar PV plant by using the DD model for instance, which is considered in this paper. The use of DD mathematical model results in a precise size for the PV array. Therefore, in this paper, multi-objectives feasibility enhanced particle swarm optimization (MOFEPSO) is used to find the aforementioned three solutions from the new Pareto frontier. MOFEPSO is used in this paper as it gradually increases the entire feasibility of the swarms to obtain superior solutions [20].

\section{Methodology}

In this paper, the objective functions will be used as couples in three scenarios. These are (TNPC vs. LPSP) in the 1st case, (ACS vs. LPSP) in the 2nd case, and (IR vs. TNPC) in the 3 rd case. MOFEPSO algorithm is used to find the Pareto front of each scenario [20]. The mathematical modelling of the system components is discussed in detail in the next section. However, this system contains different components such as PV panels, power inverter, utility grid, and biogas plant, as seen in Figure 1.

Indeed, four hourly measured input data sets are implemented in this research. These data are used to size the on-grid PV-biogas hybrid system located in Al-Ghabawi Area $\left(31^{\circ} 55^{\prime} 44.0^{\prime \prime} \mathrm{N}\right.$ and $\left.36^{\circ} 10^{\prime} 56.0^{\prime \prime} \mathrm{E}\right)$, Amman, Jordan. These input data sets were gained from formal institutions in Jordan for the whole year of 2020. Hence, hourly solar horizontal irradiance $\left(S_{\text {horizontal }}\right)$ represented by $\mathrm{W} / \mathrm{m}^{2}$, hourly ambient temperature $\left(T_{a m p}\right)$ represented by ${ }^{\circ} \mathrm{C}$, hourly power load demand represented by MW, and hourly Municipal Solid Wastes (MSW) represented by Gigagram (Gg) are obtained. These data will be exported to the simulation algorithms as vectors with the individual length of 8760 . Note that each vector's length is equal to the number of hours in a year, i.e., 8760 . Moreover, the time step for the measured data is one hour. This means that there are 8760 hourly measured data that have been obtained for the load demand and each renewable energy system shown in Figure 1 in 2020, see Table 1. 


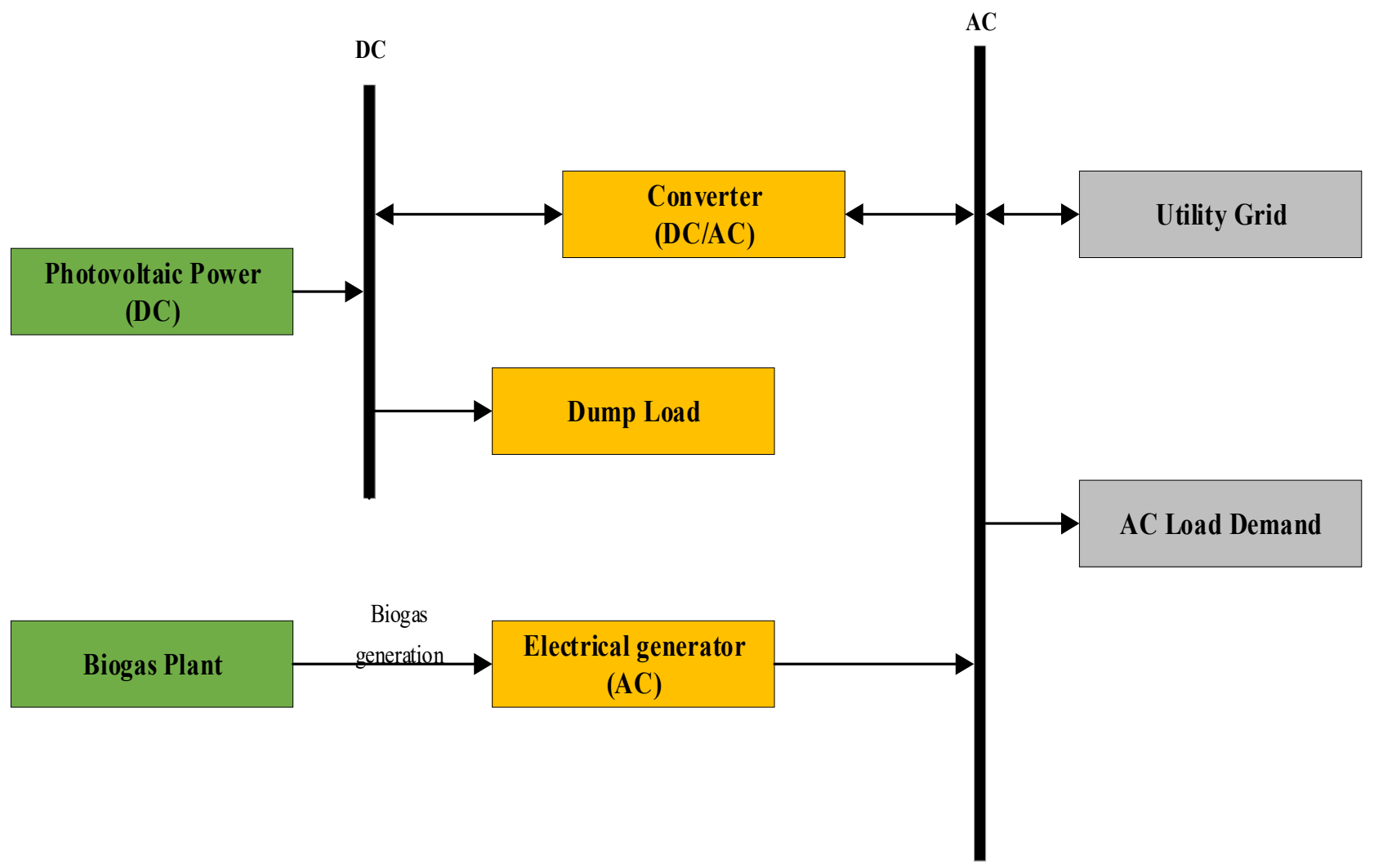

Figure 1. Schematic diagram of an on-grid PV-biogas energy system.

Table 1. Hourly series real measured data sets [21-23].

\begin{tabular}{ccc}
\hline Data & Unit & Values \\
\hline Solar irradiance & $\mathrm{kW} / \mathrm{m}^{2}$ & Set of 8760 points $(365$ days $\times 24 \mathrm{~h})$ \\
Ambient temperatures & ${ }^{\circ} \mathrm{C}$ & Set of 8760 points $(365$ days $\times 24 \mathrm{~h})$ \\
Municipal solid wastes & $\mathrm{Gg}$ & Set of 8760 points $(365$ days $\times 24 \mathrm{~h})$ \\
Load demand & $\mathrm{MW}$ & Set of 8760 points $(365$ days $\times 24 \mathrm{~h})$ \\
\hline
\end{tabular}

\subsection{Solar Data}

$S_{\text {horizontal }}$ and $T_{a m p}$ are obtained on an hourly basis, as shown in Figure 2 . The minimum, maximum, and average numerical solar horizontal irradiance values are 0, 1195.8, and $273.98 \mathrm{~W} / \mathrm{m}^{2}$, respectively, as depicted in Figure 2. These data are collected from the Jordanian energy center, which is part of the Royal Scientific Society institution [21]. It is one of the important scientific research centers in Jordan which was established in 1970. It consists of 7 technical departments with 38 specialized testing laboratories.

\subsection{Power Load Demand}

The hourly load demanding power values of Al-Ghabawi of $33 \mathrm{kV}$ sub-feeder are obtained from the National Electrical Power Company (NEPCO) [22]. NEPCO is the prime provider and distributor of electricity in Jordan. The minimum, maximum, and average numerical load demand values are 0.901, 5.4969, and 3.0264 MW, respectively, as shown in Figure 2. The HRES is designed to cover the load demand of Al-Ghabawi territory in this study. 


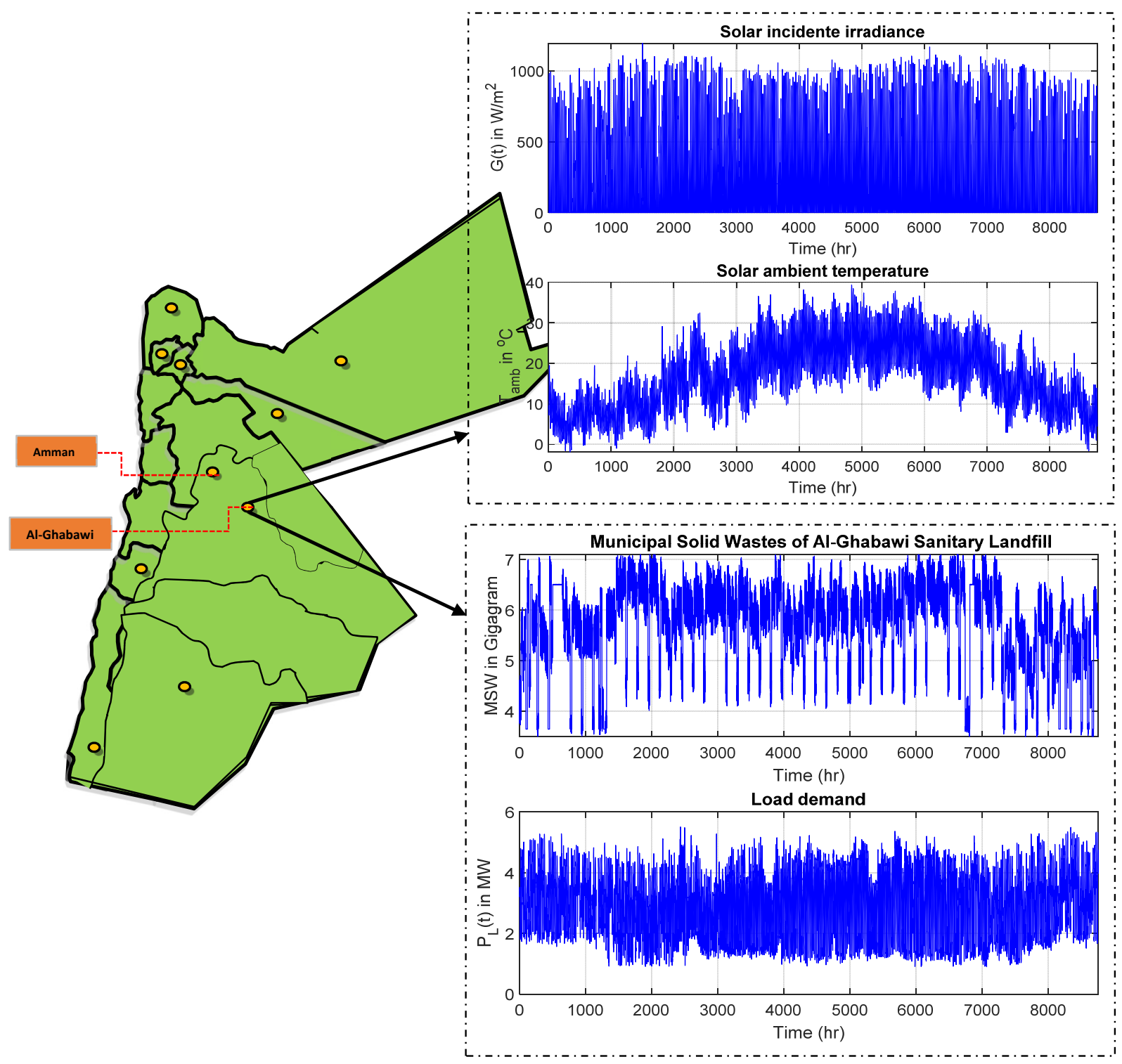

Figure 2. Hourly real measured solar irradiance, ambient temperature, municipal solid wastes, and load demand in 2020 for Al-Ghabawi Area, Amman, Jordan.

\subsection{Municipal Solid Wastes}

The daily quantities of municipal solid waste (MSW) of Al-Ghabawi sanitary landfill site are obtained from the Ministry of Environment [23]. This sanitary landfill is considered the first largest landfill in Jordan, and it is found in the middle region of Jordan near Amman $[24,25]$. The minimum, maximum, and average numerical MSW values are 3.501, 7.099 , and $5.723 \mathrm{Gg}$, respectively, as shown in Figure 2.

The steps of this study are highlighted and summarized as shown in the flow diagram of Figure 3. Firstly, hourly input real measured data were conducted from formal Jordanian institutions to design the mathematical models realistically. Accordingly, these data were gathered to optimize the large-scale grid-connected PV-biogas system for the chosen location in Jordan. For instance, the output solar PV power was obtained from the hourly metrical solar irradiance and ambient temperature values. These data were utilized in the DD solar PV realistic model to hourly attain the output PV power. 


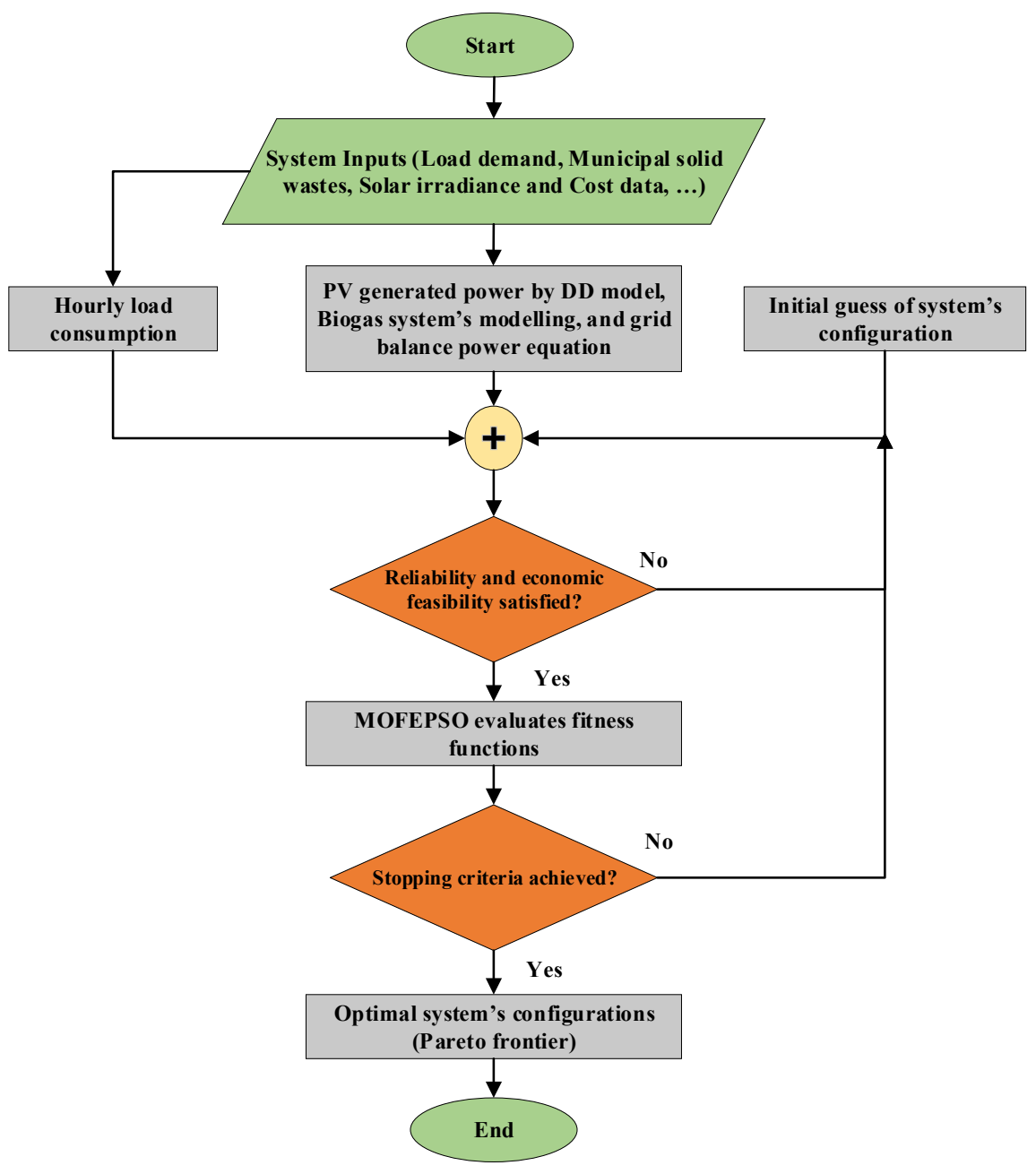

Figure 3. Steps of research progress for the proposed system.

Secondly, a recently developed optimization algorithm, called MOFEPSO, was adopted in this study. The MOFEPSO technique was used to find the optimal system configurations of the proposed system. It aims to comprehensively investigate the model and attain the system in terms of economic feasibility and reliability. It is worth noting that all the Pareto points are considered solutions to the multi-objective problem described in this paper. Additionally, the parameters of the system were determined at three Pareto points. These are the most reliable, affordable, and best optimal solutions. The basis to find the reliable solution is to have the highest value of IR or the lowest value of LPSP. The basis to obtain the affordable solution is to have the lowest value of TNPC or the lowest value of ACS. The basis to have the best optimal solution is to have a compromised solution that is accepted from both the reliability and affordability points of view.

As a matter of fact, there is a trade-off relationship between reliability and cost issues. Furthermore, the interest in one of these issues depends on the design engineers and decision makers. Moreover, in many cases that have been used in the literature, the focus was on affordability, while in other studies, the focus was on reliability. However, in this research, the researchers have the chance to select the solution from the Pareto front based on their interest and based on what the decision makers are interested in. For instance, if they are concerned about reliability, then the reliable solution is evaluated with all the corresponding solutions. On the other hand, the affordable solution is assessed if they are interested in economic feasibility. Finally, if they are trying to find a compromised solution that is accepted from both economic and reliable points of view, then the best optimal solution is considered. In other words, three scenarios for the multi-objective problem were 
implemented to obtain optimal cost-effective and reliable solutions. Moreover, the fuzzy logic method was implemented to find the best optimal non-dominant solution at each Pareto front curve. Finally, system energies, cost, ecological, and reliability technical indices were computed for each aforesaid solution in each Pareto front.

\section{Mathematical Modeling}

In this section, the mathematical formulation of the grid-connected HRES will be discussed. Modeling of the system is fundamental to build the optimization code for the proposed system in Figure 1.

\subsection{PV Output Power}

In this paper, the output PV power is computed using the PV DD model. It is an accurate PV model and it is sometimes called the two-diode model [18]. The DD model takes into account both the diffusion and recombination actions. The equivalent circuit of the DD models is shown in Figure 4 [26]. The first diode, $D_{1}$, represents the diffusion action of the minority carriers into the depletion layer, while the diode $D_{2}$ refers to the recombination action in the space charge region of the PN junction [27].

The DD model is a modified version of the single diode (SD) circuit topology. It is important to mention that the single diode circuit PV model does not consider the effect of recombination action. Many RE research studies adopt the SD solar PV circuit [28-32]. However, the DD model is more precise as it considers the aforementioned physical actions. This results in an accurate size of the PV plant, and thereby the size, economic feasibility, reliability, and ecological impacts will be precisely calculated [33-36]. The output current $\left(I_{\text {out }}\right)$ of the DD model will be used to calculate the output PV power in (9), of the proposed system. $I_{\text {out }}$ can be computed as in $(1)[37,38]$. The solar PV module implemented in this study is manufactured by Antaris Solar (SM 250PC8). The rated power of the designated PV module is $250 \mathrm{~W}$.

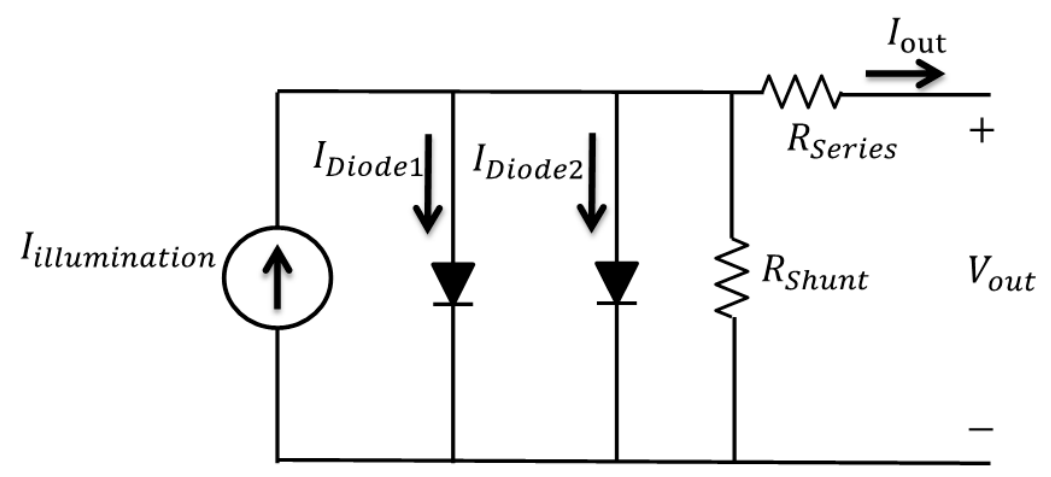

Figure 4. Equivalent circuit of a DD solar PV module [39].

$$
I_{\text {out }}=I_{\text {illumination }}-I_{\text {Diode } 1}-I_{\text {Diode2 }}-I_{\text {Shunt }}
$$

where $I_{\text {Diode1 }}, I_{\text {Diode2 }}$, and $I_{\text {Shunt }}$ are found as in (2), (3), and (4), respectively $[34,37,40]$. The PV module's illumination current is linearly dependent on solar irradiance, and it is also impacted by temperature, as observed in (5) [35,36,38,41].

$$
\begin{gathered}
I_{\text {Diode } 1}=I_{O_{1}}\left(e^{\left(\frac{V_{\text {out }}+I_{\text {out }} R_{\text {series }}}{\alpha_{1} V_{T}}\right)}-1\right) \\
I_{\text {Diode } 2}=I_{O_{2}}\left(e^{\left(\frac{V_{\text {out }}+I_{\text {out }} R_{\text {series }}}{\alpha_{2} V_{T}}\right)}-1\right) \\
I_{\text {Shunt }}=\frac{V_{\text {out }}+I_{\text {out }} R_{\text {series }}}{R_{\text {shunt }}}
\end{gathered}
$$




$$
\begin{aligned}
& I_{\text {illumination }}=\left[I_{p v_{S T C}}+K_{I}\left(T-T_{S T C}\right)\right] \frac{G}{G_{S T C}} \\
& \text { After substituting Equations (2)-(4) in (1), Equation (1) is rewritten as in (6). Further- } \\
& \text { more, the diode reverse saturation current } I_{o} \text { depends on temperature and can be found } \\
& \text { as in (7), where } E_{g} \text { is the bandgap energy of the semiconducting material and } I_{o, S T C} \text { is the } \\
& \text { nominal saturation current and can be quantified by }(8) \text {, at the standard test conditions. } \\
& I_{\text {out }}=I_{\text {illumination }}-I_{O_{1}}\left(e^{\left(\frac{V_{\text {out }}+I_{\text {out }} R_{\text {series }}}{\alpha_{1} V_{T}}\right)}-1\right)-I_{O_{2}}\left(e^{\left(\frac{V_{\text {out }}+I_{\text {out }} R_{\text {series }}}{\alpha_{2} V_{T}}\right)}-1\right)-\frac{V_{\text {out }}+I_{\text {out }} R_{\text {series }}}{R_{\text {shunt }}} \\
& I_{0}=I_{o, S T C}\left(\frac{T_{S T C}}{T}\right)^{3} \exp \left(\frac{q E_{g}}{\alpha K}\left(\frac{1}{T_{n}}-\frac{1}{T}\right)\right) \\
& I_{O_{S T C}}=\frac{I_{S C_{S T C}}}{\exp \left(\frac{V_{\text {ocSTC }}}{\alpha V_{T_{S T C}}}\right)-1}
\end{aligned}
$$

The DD model is sometimes named as the seven parameters model [42]. The output power of the PV module (in $\mathrm{kW}$ ) with the use of the DD model is computed using (9) [39].

$$
P_{P V}(t)=V_{\text {out }}\left(I_{\text {illumination }}-I_{O_{1}}\left(e^{\left(\frac{V_{\text {out }}+I_{\text {out }} R_{\text {series }}}{\alpha_{1} V_{T}}\right)}-1\right)-I_{o_{2}}\left(e^{\left(\frac{V_{\text {out }}+I_{\text {out }} R_{\text {series }}}{\alpha_{2} V_{T}}\right)}-1\right)-\frac{V_{\text {out }}+I_{\text {out }} R_{\text {series }}}{R_{\text {shunt }}}\right)
$$

Note that the solar output PV power values, computed using (9), are forwarded in the model to find the output inverted power shown in (11). This inverted power is used in the power balance strategy of the optimized system, as seen in (23).

\subsection{Biogas Generator Output Power}

The biogas plant shown in Figure 1 produces the biogas through the fermentation process of the organic materials fired inside the AC generator to produce electrical energy. Equation (10) is used to find the size of the AC generator that could be mounted in a particular location, i.e., Al-Ghabawi Area [43]. This biogas power is used in the power balance equation, as shown in (23).

$$
P_{\text {biogas plant }}(t)=\frac{V_{\text {biogas }}(t) \times C V_{\text {biogas }} \times \eta_{\text {biogas plant }}}{860 \times t_{\text {biogas plant }}}
$$

where $P_{\text {biogas plant }}(t)$ is the rated output power of biogas plant (in $\left.\mathrm{kW}\right), V_{\text {biogas }}(t)$ is the volume of the produced biogas (in $\mathrm{m}^{3}$ /day), $C V_{\text {biogas }}$ is the calorific value of the available biogas (in $\mathrm{kcal} / \mathrm{m}^{3}$ ), $\eta_{\text {biogas plant }}$ is the efficiency of the biogas plant (in $\%$ ), and $t_{\text {biogas plant }}$ is the number of daily working hours of the biogas plant, which is used as a decision variable in this research article (in $\mathrm{h} /$ day).

\subsection{Inverter Output Power}

The DC electrical power generated using the solar PV array is converted to an AC power using the power inverter, as (11) revealed [44]. This inverted solar PV power will be used in the balance equation of the energy management strategy as noticed in (23).

$$
P_{\text {inv }}(t)=P_{P V}(t) \times \eta_{\text {inv }} \times N_{P V} \times f_{P V}
$$

where $P_{i n v}(t)$ is the inverter output power which is used to determine the maximum converted power, $N_{P V}$ is a decision variable, in this paper, representing the number of $\mathrm{PV}$ panels of the optimized system, $f_{P V}$ is the derating percent in the solar PV panels, and $\eta_{i n v}$ is the efficiency of the power inverter (in \%). 


\subsection{Cost}

\subsubsection{Annualized Cost of the System}

The annualized cost of the system (ACS) in USD/yr indicates the annualized cost of the system's components which are solar PV panels, power inverters, biogas plant, costs of energy sold to the grid, and the purchased power from the grid in this system as shown in (12) [14]. ACS is one of the objective functions to be optimized in the second case scenario. The resulting Pareto front of this scenario relates ACS with LPSP as an explanation for the relationship between system's affordability and reliability, respectively.

$$
\mathrm{ACS}=N_{p v} \times A C_{P V}+P_{b i o g a s} \times A C_{b i o g a s}+P_{i n v} \times A C_{i n v}+C_{g p}-C_{g s}
$$

where $A C_{P V}$ is the total annualized cost of PV panel (in (USD/kW)/yr) including the annual capital and maintenance costs of the PV system. $A C_{\text {biogas }}$ is the total annualized cost of biogas plant (in (USD/kW)/yr) and it includes the annual capital, replacement, maintenance, fuel, and salvage costs of the biogas generator. $A C_{i n v}$ is the total annualized cost of power inverter (in (USD/kW)/yr) and it includes the annual capital, replacement, maintenance, and salvage costs of the power inverter. $C_{g p}$ is the annual cost of grid energy purchases (in USD/yr), and $C_{g s}$ is the annual cost of grid energy sales (in USD/yr).

\subsubsection{Total Net Present Cost}

The total net present cost (TNPC) in USD of the investigated system is the present cost of the entire system's components that is endured during the project lifetime. This includes capital cost $(\mathrm{CC})$, replacement cost $(\mathrm{RC})$, operational and maintenance cost $(\mathrm{OMC})$ and salvage cost value (SC) of the components, taking into consideration the time value of the money. TNPC is one of the optimized objective functions used in the first scenario (TNPC vs. LPSP) and third scenario (IR vs. TNPC). TNPC can be calculated using (13). $\operatorname{CRF}(r, M)$ is the capital recovery factor value, and it can be found using (14). Where $r$ is the real interest rate (in \%), and $M$ is the project lifetime (in years).

$$
\begin{gathered}
T N P C=\frac{A C S(U S D / y r)}{C R F(r, M)} \\
\operatorname{CRF}(r, M)=\frac{r(1+r)^{M}}{(1+r)^{M}-1}
\end{gathered}
$$

\subsubsection{Levelized Cost of Energy}

Levelized cost of energy (LCOE) in USD/kWh is defined as the ratio of the ACS of the system's components divided by the energy produced by renewables and consumed by the load demand through one year $(\mathrm{kWh} / \mathrm{yr})$. It is one of the well-known economic feasibility indicators, and it has been computed in each of the three Pareto front solutions in the three optimized scenarios using (15) [41]. LCOE presents the average value per kWh of the energy produced by the HRES.

$$
L C O E=\frac{A C S(U S D / y r)}{\text { Total Energy Consumed by the Load }(k W h / y r)}
$$

\subsection{Reliability Indicators}

The reliability of an energy system is defined as the ability of the HRES to meet the load demand with sufficient energy without any deficit or interruption in the service. There are many system's reliability indices. The most common ones are EENS and LPSP [45], Index of Reliability (IR) [46], LOLP [47], and Loss of Load Expectation (LOLE). These indices give an indication of how much the load is satisfied. EENS can be found mathematically using (16) by finding the amount of energy shortage in the load $[48,49]$, where $P_{L}(t)$ is the 
power of the load demand (in $\mathrm{kW}$ ) and $P_{g p}(t)$ is the quantity of power purchased by the utility grid (in $\mathrm{kW}$ ).

$$
E E N S=\sum_{t=1}^{8760}\left[P_{L}(t)-\left(P_{i n v}(t)+P_{g p}(t)+P_{\text {biogas }}(t)\right)\right]
$$

LPSP can be found using (17) by dividing the EENS by the overall energy delivered to the load demand. This reliability index is used to measure the HRES's ability to supply the load without incurring any energy deficit, as presented in (18) [39,50].

$$
\begin{aligned}
L P S P & =\frac{E E N S}{\sum_{t=1}^{8760} P_{L}(t)} \\
I R & =1-L P S P
\end{aligned}
$$

$L O L P$ can be calculated arithmetically by dividing the number of hours when the power of the load demand is greater than the power coming from both renewables and grid purchases, to the entire time in hours which is 8760 as in (19) [48]. The range of LPSP and LOLP indices are between 0 and 1 . The value of 0 means that there is no energy deficit at all. The value of 1 indicates that there is always an energy shortfall in each time step of one hour. LOLE represents service interruption in days, which is calculated using (20).

$$
\begin{gathered}
L O L P=\frac{\sum_{t=1}^{8760} \text { hours\# at }\left[P_{L}(t)>\left(P_{\text {inv }}(t)+P_{g p}(t)+P_{\text {biogas }}(t)\right)\right]}{8760} \\
\text { LOLE }=L O L P \times \text { Number of days in one year }
\end{gathered}
$$

It is worth mentioning that Equations (16), (19), and (20) are computed at each set of solutions of the Pareto frontier in the three aforesaid case scenarios. This is to give more insight regarding system's reliability. Note that LPSP and IR in Equations (17) and (18), respectively, are considered as the reliability objective functions in one or more of the optimized three scenarios.

\subsection{Environmental Indicators}

The projected direct and indirect $\mathrm{CO}_{2}$ greenhouse gas (GHG) in 2025 is around $29 \mathrm{k}$ gigagrams $(\mathrm{Gg})$ in Jordan. The main contributor of these GHG emissions comes from the electrical sector, with around 43\% [51]. The Jordanian Ministry of Environment tries to follow an energy management strategy that mitigates emissions by reducing the energy purchased from the utility grid. This is as the primary source for electricity generation in Jordan is natural gas. Thus, this paper investigates the impact of considering the hybrid solar PV biogas system on minimizing grid energy purchases.

In this paper, Equation (21) will be used to hourly estimate GHG emissions [52]. Furthermore, Equation (22) presents the project emissions alleviation. These two equations will be calculated in the three case scenarios of the Pareto front solutions. This is to give more explanation regarding the environmental impact of the retrofitting RE system. $P_{E A}$ is defined as the amount of emissions that have been mitigated as a result of using renewables instead of generating electricity from conventional fossil fuels sources [52].

$$
\begin{gathered}
\text { Emissions }=\frac{E_{g p} \times \mathrm{EEF}}{1-T \& D} \\
P_{E A}=\left(E_{P V}+E_{B i o}\right) \times E E F-\text { Base }_{\text {emissions }}
\end{gathered}
$$

where $T \& D$ is the transmission and distribution losses, and $E E F$ is the electrical emission factor representing $14.57 \%$ and $0.643924 \mathrm{tCO}_{2} / \mathrm{MWh}$ [23,51]. However, Base emissions is the project emissions, which is considered as a tiny amount compared with the amount of emissions mitigated by RE resources as in (22). Note that Base $e_{\text {emissions }}$ from RE resources 
are considered in this paper due to their production and lifetime. Thereby, in this research, the total base emissions of solar PV and biogas plants are equal to $71 \mathrm{gCO}_{2} / \mathrm{kWh}$ [53-55].

\subsection{System's Operational Power Strategies}

In this study, the multi-objective functions include three scenarios. TNPC vs. LPSP as the first scenario, ACS vs. LPSP in the second scenario and IR vs. TNPC in the third scenario. The justifications behind using the aforementioned three multi-objective scenarios are as follows. First, several literature studies used only one case scenario, which will not fully indicate the system's robustness. Second, the adoption of these three scenarios in three different regions on the Pareto front will indicate all possible solutions of the multiobjective optimization problem. This helps researchers, design engineers, and decision makers who are interested in the solution in one of these regions. For instance, there is a trade-off relationship between TNPC and IR indices. Furthermore, the concerns to one of these indices depend on the design engineers and decision makers. In this paper, they can select the affordable solution that has the lowest value of TNPC if they are interested in the system's affordability. Furthermore, they can select the solution with the highest value of IR if they are concerned about the system's reliability. Moreover, the best optimal solution is the best choice if the design engineers are interested in both economic feasibility and system's reliability. In fact, utilizing this multi-criteria of the optimization problem will provide a better observation and a clear vision for the proposed solutions of the multi-objective optimization problem [56,57]. Accordingly, the decision variables are the total number of PV panels $\left(N_{P V}\right)$, and the number of operating hours $\left(t_{\text {biogas plant }}\right)$ of the biogas energy system. Thus, the system configuration will be found for the three scenarios considering technical equality and inequality constraints. In other words, MOFEPSO evaluates all possible solar configurations and total operated biogas plant working hours per day to sufficiently satisfy the load demand of Al-Ghabawi Area. The power balance equality equation of the entire hybrid PV-biogas on-grid system is given by (23). Indeed, Equation (23) is the key point representing the energy management strategy tested at each hourly time step. This is an essential step prior the optimization process seen in (27) of Section 4.

$$
P_{\text {inv }}(t)+P_{\text {biogas plant }}(t)+P_{\text {grid purchases }}(t)=P_{\text {grid sales }}(t)+P_{\text {Load }}(t)+P_{\text {dump }}(t)
$$

The exploited inverted power from PV arrays $\left(P_{\text {inv }}\right)$ is computed using $(11)$, and $P_{\text {biogas plant }}$ is calculated as mentioned in (10). Indeed, at each hourly time step, whenever $P_{i n v}$ is not sufficient to cover the load, $P_{\text {biogas }}$ plant starts operating to meet the power deficit. On the one hand, when both aforementioned power values cannot meet the demand, the power deficit will be brought from the grid, as per (24). However, if there are additional solar and/or biogas power values after satisfying the load demand, the surplus energy will be sold to the grid, as in (25). However, a deficit occurs when reaching the maximum power grid purchasing capacity as in (26) [22]. Finally, after reaching the maximum selling limit, the additional power will be dumped [19]. The equality power Equations of (24)-(26) are actually used in (28) as the equality constraints of the MOFEPSO algorithm.

$$
\begin{gathered}
P_{\text {grid purchases }}(t)=P_{\text {Load }}(t)-P_{\text {inv }}(t)+P_{\text {biogas plant }}(t) \\
P_{\text {grid sales }}(t)=P_{\text {inv }}(t)+P_{\text {biogas plant }}(t)-P_{\text {Load }}(t) \\
P_{\text {maximum purchases }}=15 \% \times \eta_{\text {Trans }} \times P_{R_{\text {Trans }}}
\end{gathered}
$$

\section{System's Optimization}

\subsection{MOFEPSO Algorithm}

MOFEPSO is an enhanced constrained technique built based on the feasibility enhanced particle swarm optimization. Hasanoglu and Dolen developed it to deal with multi-objective problems that have constraints [20]. This technique works only with in- 
equality constraints, so all the equality constraints are generally transformed to inequality constraints. However, the constrained two-objective optimization problem for the three combinations has been taken into consideration as shown in (27), subject to the inequality $(g)$ and equality $(h)$ constraints as seen in $(28)[20,58]$.

$$
\begin{gathered}
f(x)=[(\operatorname{TNPC}(\mathrm{x}) \| \operatorname{ACS}(x)),(\operatorname{LPSP}(\mathrm{x}) \| \operatorname{IR}(x))]^{T} \\
\left\{\begin{array}{c}
g_{m}(x) \leq 0,0<m \leq M \\
h_{p}(x)=0,0<p \leq P
\end{array}\right.
\end{gathered}
$$

where $\mathrm{x}$ are the decision variables, i.e., $x=\left[N_{P V}, t_{\text {biogas }}\right]^{T}$, and $M$ and $P$ are the numbers of inequality and equality constraints, respectively.

The detailed operational strategies of the MOFEPSO algorithm are explained as follows. Firstly, the initialization will be performed for all parameters starting with the first particle in the first iteration. Secondly, the current position of the particle is checked for feasibility. If it is a feasible position, the feasible velocity and the particle flight manner will be updated. If the position is not feasible, the infeasible velocity and particle flight manner will be updated. Accordingly, the new position of the particle is double checked for feasibility. On the one hand, MOFEPSO will calculate the objective vector (TNPC, ACS, with IR or LPSP) and add the current solution to the best set of solutions. Subsequently, it will update the best solution in the objective vector if it is not dominant by any other solutions. If the new particle position is not the best, MOFEPSO will test if it is not the last particle. Moreover, if it is not the last iteration, MOFEPSO will redo the previous steps following the initialization. Finally, if the stopping criteria for the number of particles and iteration are met, MOFEPSO will present all the feasible sets of non-dominant tradeoff solutions as Pareto front [59].

Indeed, MOFEPSO does not require any initialization swarm for feasible solutions. Furthermore, the objective functions are not evaluated based on the infeasible particles. The particles can only move along with sensitive directions, and particles are not allowed to move to a position where any previously satisfied constraints become violated. Hence, distinctive features help MOFEPSO progressively increase the global feasibility of the swarms and finally attain better optimal solutions [20].

Moreover, many optimization problems include numerous objective functions that usually conflict in their nature. These problems may include lots of constraints that will eventually reduce the feasible solutions in the multi-dimensional search space [58]. The concepts of global non-dominated sets/positions (gbest) and personal non-dominated sets/positions (pbest) are used to initialize the particles and move them to their feasible positions in order to find the best solution in the swarm [59]. To sum up, these unique features help MOFEPSO algorithm increase both overall performance and feasible optimal solutions.

\subsection{Validation Procedure}

Many common approaches can find the best non-dominant solution, such as the fuzzy logic method. The fuzzy logic method uses the fuzzy membership function $\mu_{i}\left(F_{i}\right)$ to find the best non-dominant solution out of all non-dominant solutions stored in the archive [60]. The fuzzy membership function in (29) is used to convert each objective function $\left(F_{i}\right)$ to a membership value in range between $(0,1)[61]$. Where $F_{i}^{\text {min }}$ and $F_{i}^{\text {max }}$ represent the minimum and maximum objective function values, respectively.

$$
\mu_{i}\left(F_{i}\right)=\left\{\begin{aligned}
1, F_{i}(x) & \leq F_{i}^{\text {min }} \\
0, F_{i}(x) & \geq F_{i}^{\text {max }} \\
\frac{F_{i}^{\text {max }}-F_{i}(x)}{F_{i}^{\text {max }}-F_{i}^{\text {min }}}, F_{i}^{\text {min }} & \leq F_{i}(x) \leq F_{i}^{\text {max }}
\end{aligned}\right.
$$


In this study, a multi-objective optimization is performed to find three solutions which are the reliable, affordable, and best solutions. Equation (30) is used to minimize $f_{1 a}(x)$ and $f_{1 c}(x)$, whereas (31) is used to minimize $f_{1 b}(x)$ and $f_{1 c}(x)$. Further, (32) is used to minimize $f_{1 d}(x)$ and $f_{1 a}(x)$. Note that $f_{1 a}(x)$ and $f_{1 b}(x)$, shown in (33) and (34), are minimization to TNPC and ACS as economic evaluation indicators, whereas $f_{1 c}(x)$ is a minimization to the LPSP as a reliability evaluation indicator as shown in Equation (35). Note that the reciprocal is taken in (36) in order to maximize the objective function of IR in the third scenario. The optimization of these objective functions is subjected to the constraints shown in (37). The decision variables are given by (38).

$$
\begin{gathered}
\text { Minimize } F_{1}(X)=\left[f_{1 a}(x), f_{1 c}(x)\right] \\
\text { Minimize } F_{2}(X)=\left[f_{1 b}(x), f_{1 c}(x)\right] \\
\text { Minimize } F_{3}(X)=\left[f_{1 d}(x), f_{1 a}(x)\right] \\
f_{1 a}(x)=(T N P C) \\
f_{1 b}(x)=(A C S) \\
f_{1 c}(x)=(\operatorname{LPSP}) \\
f_{1 d}(x)=\left(\frac{1}{I R}\right) \\
1 \leq N_{p v} \leq N_{p v}^{\text {maximum }} \\
1 \leq P_{\text {biogas plant }} \leq P_{\text {biogas }}^{\text {maximum }} \\
P_{\text {grid purchases }} \leq P_{g p}^{\text {maximum }} \\
P_{\text {grid sales }} \leq P_{g s}^{\text {maximum }} \\
X=\left[N_{\text {pv }}, t_{\text {biogas plant }}\right]
\end{gathered}
$$

The energy management operation strategy of the grid-connected PV-biogas is started by setting the input measured data. Then, the optimization begins by sizing the PV system as a priority. If the energy coming from the PV system is greater than the load demand, then the additional energy will be sold to the grid within the maximum grid sales capacity. On the other hand, if the PV energy is insufficient, the load will be served by both the PV system and biogas generator. If renewable power is not adequate, the utility grid will provide energy to the load demand within the maximum grid purchase capacity. After that, the optimal configuration of the system parameters is found [19]. This strategy clearly shows the process to reach the best configurations of TNPC versus LPSP in a case, ACS versus LPSP and IR versus TNPC in other cases, which will be considered as Pareto points on the Pareto frontier.

\section{Results and Discussion}

The optimization algorithm method which is used to test the validity of the proposed system is the MOFEPSO [20]. Three concerns are taken into consideration in the optimization of (TNPC or ACS with LPSP or IR) for the on-grid system which are reliable, affordable, and best solutions. Those three concerns are considered in this research as there is a trade-off relationship between system's reliability and economic feasibility. The result of the MOFEPSO will be Pareto frontier showing non-dominant solutions. Therefore, based on the interests of the decision makers and design engineers, they can choose any of these solutions. For example, if they are concerned about system's reliability, then the reliable solution is evaluated with all the corresponding reliable, economic, and environmental solutions. On the other hand, if the target is the economic feasibility, then the affordable solution is assessed. Accordingly, if a compromised solution is requested between both system's affordability and reliability, then the optimal best solution will be the best approach to select. 
Figure 5 presents the Pareto front curve of the first scenario (TNPC vs. LPSP). The optimization results for the three mentioned concerns are presented in Table 2. At each point, the energy results, reliability, feasibility, and environmental numerical findings are provided. Further, the values of the decision variables are presented, which are $N_{p v}$ and $t_{\text {biogas plant }}$ in this case.

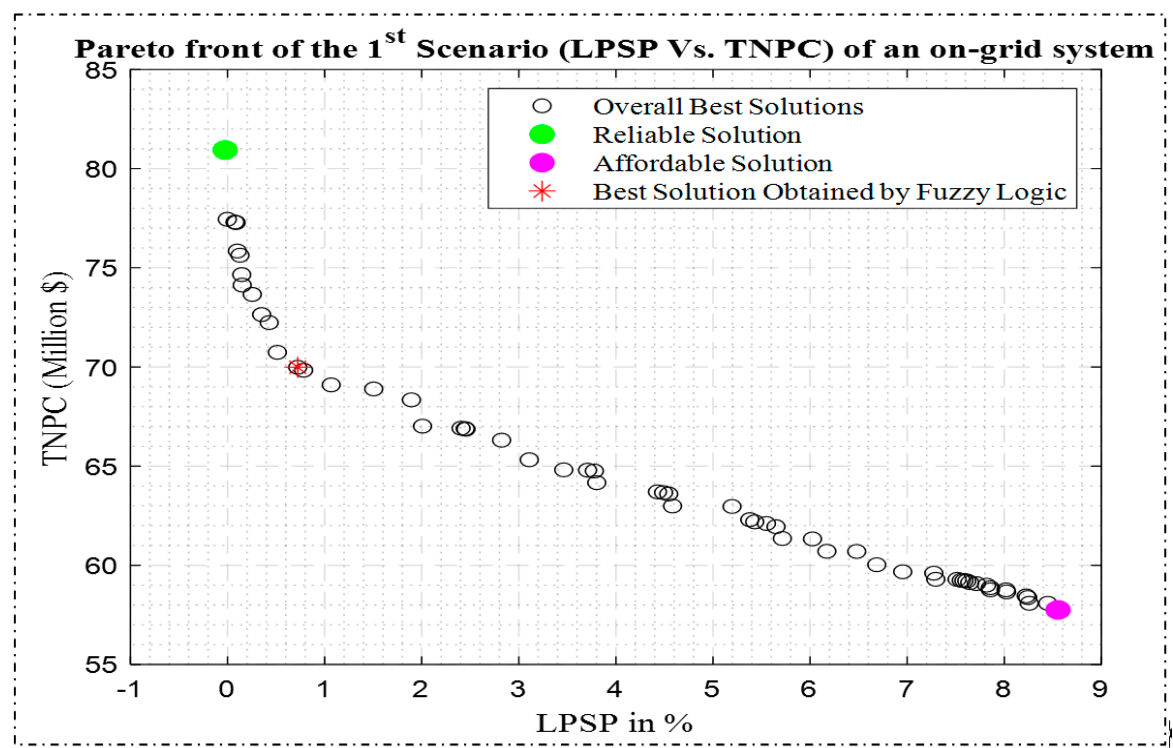

Figure 5. Pareto front curve for the first scenario of TNPC versus LPSP obtained by MOFEPSO.

Table 2. Optimization results of the first scenario (TNPC vs. LPSP) at the selected solutions.

\begin{tabular}{|c|c|c|c|}
\hline \multirow{2}{*}{ Parameter } & \multicolumn{3}{|c|}{ MOFEPSO } \\
\hline & Reliable & Affordable & Best \\
\hline LPSP (\%) & 0.0238 & 8.5758 & 0.72258 \\
\hline TNPC (Million USD) & 81.219 & 57.769 & 69.988 \\
\hline$N_{p v}$ & 35,731 & 28,625 & 29,137 \\
\hline$t_{\text {biogas plant }}(\mathrm{h} /$ day $)$ & 3.3884 & 24 & 6.1879 \\
\hline$E_{i n v}(\mathrm{GWh})$ & 19.1381 & 15.332 & 15.606 \\
\hline$E_{\text {biogas }}(\mathrm{GWh})$ & 14.356 & 2.11524 & 8.1706 \\
\hline$E_{\text {Renewables }}(\mathrm{GWh})$ & 33.4936 & 17.4472 & 23.7768 \\
\hline$E_{\text {grid purchases }}(\mathrm{GWh})$ & 5.4027 & 14.4818 & 10.791 \\
\hline$E_{\text {grid sales }}(\mathrm{GWh})$ & 11.40675 & 7.63882 & 8.2346 \\
\hline$E_{\text {Total-Load }}(\mathrm{GWh})$ & 26.5115 & 26.5115 & 26.5115 \\
\hline ACS (Million USD/yr) & 7.081 & 5.0366 & 6.1019 \\
\hline LCOE (USD/kWh) & 0.2671 & 0.189976 & 0.23016 \\
\hline EENS (GWh) & 0.0063197 & 2.26722 & 0.19206 \\
\hline LOLP (\%) & 0.3995 & 0.382192 & 0.11861 \\
\hline LOLE (days) & 1.4582 & 1.395 & 0.54834 \\
\hline $\operatorname{IR}(\%)$ & 99.976 & 91.422 & 99.277 \\
\hline Annual biogas working hours & 5779 & 6030 & 6006 \\
\hline Emissions (Gg/year) & 4.0722 & 10.91556 & 8.1339 \\
\hline$P_{E A}(\mathrm{Gg} /$ year $)$ & 19.189 & 9.996 & 13.6223 \\
\hline
\end{tabular}

In terms of the best solution obtained by fuzzy logic method, TNPC and LPSP values are affordable and reliable solutions to a certain degree, where LPSP is equal to $0.72258 \%$. At the same time, TNPC is equal to USD 69.988 million. In addition, the LCOE value is equal to $0.23016 \mathrm{USD} / \mathrm{kWh}$. The values of the decision variables at the best solution are 29,137 PV panels and 6.1879 h/day. In the case of the best solution of the first scenario, the total energy generated by the PV system and biogas generator are equal to 15.606 GWh and $8.1706 \mathrm{GWh}$, respectively. In addition, the total energy purchased from the utility grid is equal to $10.791 \mathrm{GWh}$, while the total energy sold to the grid is equal to $8.2346 \mathrm{GWh}$. Moreover, the GHG emissions reduction is $13.6223 \mathrm{Gg}$ /year. These findings indicate that 
the proposed system is environmentally friendly and will reduce the amount of pollution emitted into the atmosphere.

Furthermore, the second scenario represents the relationship between ACS and LPSP for the proposed system. As discussed in the first scenario, three concerns were considered, as depicted in Figure 6.

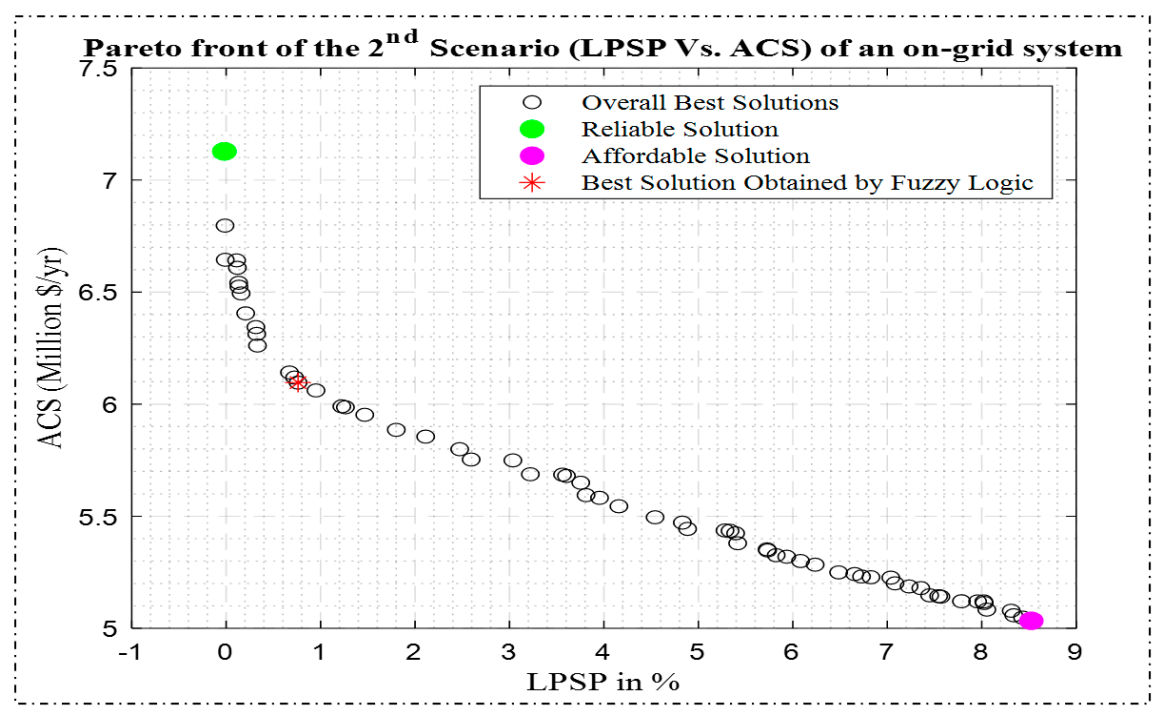

Figure 6. Pareto front curve for the second scenario of ACS versus LPSP obtained by MOFEPSO.

In this case, the ACS vs. LPSP scenario is investigated to obtain reliable, affordable, and best solutions at three different Pareto points. Table 3 represents the optimization results at the three selected points of the second scenario. The LPSP and ACS values equal $0.0016 \%$ with 7.0128 million USD/yr for the reliable solution, $8.5184 \%$ with 5.0341 million USD/yr for the affordable solution, and 0.76102\% with 6.0964 million USD/yr for the best solution. At the best solution, the annual biogas operating hours are $6019 \mathrm{~h}$, and the LOLE is 0.54834 day. Additionally, the annual energy production of the PV array and the biogas plant are 15.465 GWh and 8.1119 GWh, respectively. The decision variables at the best solution in this scenario are 28,873 PV panels and $6.2463 \mathrm{~h} /$ day as the $t_{\text {biogas plant }}$ value.

Table 3. Optimization results of the second scenario of the (ACS vs. LPSP) at the selected solutions.

\begin{tabular}{|c|c|c|c|}
\hline \multirow{2}{*}{ Parameter } & \multicolumn{3}{|c|}{ MOFEPSO } \\
\hline & Reliable & Affordable & Best \\
\hline LPSP (\%) & 0.0016 & 8.5184 & 0.76102 \\
\hline ACS (Million USD/yr) & 7.1282 & 5.0341 & 6.0964 \\
\hline$N_{p v}$ & 58,923 & 29,042 & 28,873 \\
\hline$t_{\text {biogas plant }}(\mathrm{h} /$ day) & 3.7966 & 24 & 6.2463 \\
\hline$E_{i n v}(\mathrm{GWh})$ & 31.5601 & 15.55535 & 15.465 \\
\hline$E_{\text {biogas plant }}(\mathrm{GWh})$ & 11.9402 & 2.108095 & 8.1119 \\
\hline$E_{\text {Renewables }}(\mathrm{GWh})$ & 43.5003 & 17.66345 & 23.5767 \\
\hline$E_{\text {grid purchases }}(\mathrm{GWh})$ & 6.427336 & 1.4458433 & 10.858 \\
\hline$E_{\text {grid sales }}(\mathrm{GWh})$ & 14.75387 & 7.806553 & 8.127 \\
\hline$E_{\text {Total-Load }}(\mathrm{GWh})$ & 26.51155 & 26.51155 & 26.51155 \\
\hline Annual biogas working hours & 5385 & 6010 & 6019 \\
\hline TNPC (Million USD) & 80.436 & 57.7407 & 69.925 \\
\hline LCOE (USD/kWh) & 0.26405 & 0.189885 & 0.22995 \\
\hline EENS (GWh) & 0.0044434 & 2.258366 & 0.1998 \\
\hline LOLP (\%) & 0.010959 & 0.383105 & 0.12169 \\
\hline LOLE (days) & 0.04 & 1.39833 & 0.54834 \\
\hline $\operatorname{IR}(\%)$ & 99.84 & 91.4816 & 99.239 \\
\hline Emissions (Gg/year) & 4.84457 & 10.89797 & 8.18434 \\
\hline$P_{E A}(\mathrm{Gg} /$ year $)$ & 24.9224 & 10.1198 & 13.5084 \\
\hline
\end{tabular}


Figure 7 shows the Pareto front of the third scenario between the objective functions of TNPC and IR. It can be noticed that this curve is different from the previous two cases, as the index of reliability (IR) has the opposite meaning of LPSP, as noticed in (18). Hence, when IR increases, the TNPC increases, and vice versa.

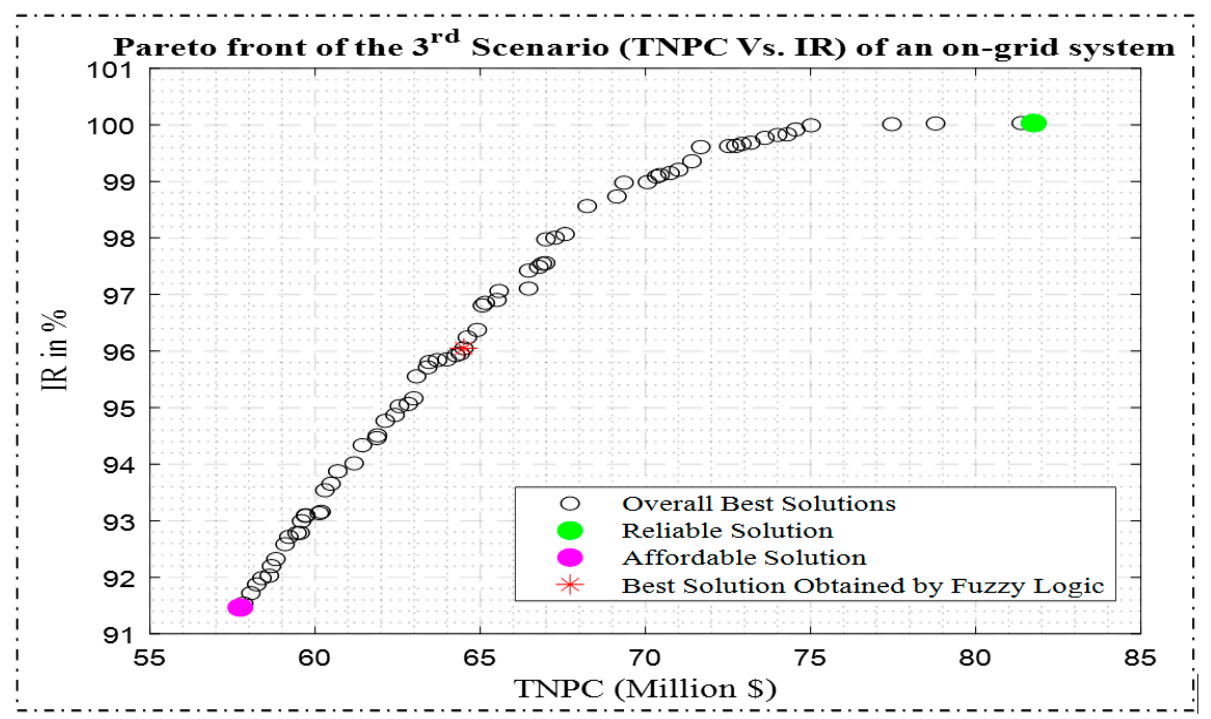

Figure 7. Pareto front curve for the third scenario of IR versus TNPC obtained by MOFEPSO.

Table 4 represents the optimization results at the three selected Pareto points. The TNPC and IR are equal to 64.504 million USD with $96.048 \%$ at the best solution. However, in the case of the reliable solution, a $99.997 \%$ of IR has been achieved, whilst the TNPC is the lowest in the affordable solution with 57.736 million USD. These results demonstrate and validate the proposed methodology. In addition, the LCOE is $0.2071 \mathrm{USD} / \mathrm{kWh}$ at the best solution, which was obtained by the fuzzy logic technique. The decision variables at the best solution of the third scenario are 33,459 PV panels and $12.498 \mathrm{~h} /$ day for the $t_{\text {biogas plant }}$ value with annual working hours of the biogas plant of $5850 \mathrm{~h}$. Finally, the amount of emission reduction is $12.5249 \mathrm{Gg}$ /year at the obtained best solution.

Table 4. Optimization results of the (IR vs. TNPC) at the selected solutions.

\begin{tabular}{|c|c|c|c|}
\hline \multirow{2}{*}{ Parameter } & \multicolumn{3}{|c|}{ MOFEPSO } \\
\hline & Reliable & Affordable & Best \\
\hline $\operatorname{IR}(\%)$ & 99.997 & 91.467 & 96.048 \\
\hline TNPC (Million USD) & 81.756 & 57.736 & 64.504 \\
\hline$N_{p v}$ & 35,495 & 29,132 & 33,459 \\
\hline$t_{\text {biogas plant }}(\mathrm{h} /$ day) & 3.6268 & 24 & 12.498 \\
\hline$E_{i n v}(\mathrm{GWh})$ & 19.012 & 15.5666 & 17.92117 \\
\hline$E_{\text {biogas plant }}(\mathrm{GWh})$ & 13.4395 & 2.107013 & 3.940154 \\
\hline$E_{\text {Renewables }}(\mathrm{GWh})$ & 32.451 & 17.67362 & 21.86132 \\
\hline$E_{\text {grid purchases }}(\mathrm{GWh})$ & 6.1346 & 14.45728 & 13.32946 \\
\hline$E_{\text {grid sales }}(\mathrm{GWh})$ & 11.149 & 7.814196 & 9.45776 \\
\hline$E_{\text {Total-Load }}(\mathrm{GWh})$ & 26.5115 & 26.5115 & 26.5115 \\
\hline ACS (Million USD/yr) & 7.1279 & 5.0338 & 5.489314 \\
\hline LCOE (USD/kWh) & 0.2622 & 0.1899 & 0.2071 \\
\hline EENS (GWh) & 0.00524 & 2.2633967 & 1.30428 \\
\hline LOLP (\%) & 0.0079 & 0.382306 & 0.2901 \\
\hline LOLE (days) & 0.5483 & 0.5483 & 0.54834 \\
\hline LPSP (\%) & 0.003 & 8.5610 & 4.8530 \\
\hline Annual biogas working hours & 5790 & 6007 & 5850 \\
\hline Emissions (Gg/year) & 4.62393 & 10.8971 & 10.047 \\
\hline$P_{E A}(\mathrm{Gg} /$ year $)$ & 18.5922 & 10.1256 & 12.5249 \\
\hline
\end{tabular}




\section{Conclusions}

This study investigates technical designs of HRES, consisting of PV-biogas hybrid energy system associated with the utility grid. This is to find the Pareto frontier using MOFEPSO algorithm, which includes reliable, affordable, and best solutions. The system inputs, including horizontal solar irradiance, ambient temperature, load demand, and municipal solid wastes, are all actual measured data for Al-Ghabawi Area, Jordan in 2020. These genuine data were used in this paper to find realistic renewable configurations for a large megawatt-scale retrofitting system. A DD solar PV model was performed to obtain the output PV power at each time step. Within this study, three different cases were investigated. These three cases are the optimization of (TNPC with LPSP), (ACS with LPSP), and (IR with TNPC). In each case, three potential solutions have been picked. The first point denotes the most reliable solution, the second denotes the most affordable solution, and the third denotes the best solution attained through the use of fuzzy logic technique. The number of PV panels $\left(N_{p v}\right)$ and the number of biogas plant working hours per day $\left(t_{\text {biogas plant }}\right)$ are considered as the decision variables in the optimization system. Based on the Pareto points obtained by MOFEPSO, it can be noticed that the highest system's reliability is attained at the extent of the high cost and large system size. In addition, the best solution approach is performed in each case to obtain a reliable and profitable solution. At the best solution in the first case scenario, the LPSP and TNPC values are $0.72258 \%$ and 69.988 million USD, respectively. The corresponding decision variables are 29,137 PV panels and $6.1879 \mathrm{~h}$ /day. In the best solution in the second case, the LPSP and ACS values are found to be $0.76102 \%$ and 6.0964 million USD/yr, respectively. The corresponding decision variables are 28,873 PV panels and $6.2463 \mathrm{~h} /$ day. Finally, in the third case, the best solution of TNPC and IR were $96.048 \%$ and 64.504 million USD, respectively with 33,459 panels and 12.498 bio-operating hours per day. Ecological system indicators and energies were found at each set of each case. For example, in the third case scenario, GHG emission reduction is $12.5249 \mathrm{Gg}$ /year, proving that the RE system is environmentally efficient. Finally, this research will hopefully encourage decision makers to adopt the performed approach in this paper to have the best solution for real-life RE applications towards both cost-effective and reliable solutions.

Author Contributions: Conceptualization, H.M.K.A.-M.; Data curation, S.K.M.; Formal analysis, H.M.K.A.-M., A.A.A.-S. and S.K.M.; Funding acquisition, A.Q.A.-S. and T.S.U.; Investigation, H.M.K.A.-M., A.A.A.-S., S.K.M. and T.S.U.; Methodology, H.M.K.A.-M., A.A.A.-S. and S.K.M.; Project administration, H.M.K.A.-M.; Resources, A.A.A.-S. and S.K.M.; Software, H.M.K.A.-M., A.A.A.-S. and S.K.M.; Supervision, H.M.K.A.-M.; Validation, H.M.K.A.-M., A.A.A.-S. and S.K.M.; Visualization, A.A.A.-S. and S.K.M.; Writing-original draft, H.M.K.A.-M., A.A.A.-S. and S.K.M.; and Writing - review and editing, A.Q.A.-S., M.G.M.A. and T.S.U. All authors have read and agreed to the published version of the manuscript.

Funding: This research received no external funding.

Acknowledgments: The authors would like to acknowledge the Jordanian institutions of Yarmouk University, Energy Center of the Royal Scientific Society, National Electric Power Company and Al-Ghabawi landfill for their support in this research paper.

Conflicts of Interest: The authors declare no conflict of interest.

\section{References}

1. Jaccard, M. Sustainable Fossil Fuels: The Unusual Suspect in the Quest for Clean and Enduring Energy; Cambridge University Press: Cambridge, UK, 2006.

2. Wuebbles, D.J.; Jain, A.K. Concerns about climate change and the role of fossil fuel use. Fuel Processing Technol. 2001, 71, 99-119. [CrossRef]

3. Demirtas, O. Evaluating the best renewable energy technology for sustainable energy planning. Int. J. Energy Econ. Policy 2013, 3, 23.

4. Girardet, H.; Mendonça, M. A Renewable World: Energy, Ecology and Equality. A Report for the World Future Council; Green Books \& Resurgence Books: Cambridge, UK, 2009.

5. Boyle, G. Renewable Energy; Oxford University Press: New York, NY, USA, 2004; p. 456. 
6. Al-Soud, M.S.; Hrayshat, E.S. A 50 MW concentrating solar power plant for Jordan. J. Clean. Prod. 2009, 17, 625-635. [CrossRef]

7. Awe, O.W.; Zhao, Y.; Nzihou, A.; Minh, D.P.; Lyczko, N. A review of biogas utilisation, purification and upgrading technologies. Waste Biomass Valorization 2017, 8, 267-283. [CrossRef]

8. Panwar, N.J.M.; Change, A.S.F.G. Design and performance evaluation of energy efficient biomass gasifier based cookstove on multi fuels. Mitig. Adapt. Strateg. Glob. Chang. 2009, 14, 627-633. [CrossRef]

9. Navani, J.; Sonal, S. Non-Conventional Energy Resources (for UPTU \& UTU), 1st ed.; S. Chand Publishing Pvt. Ltd.: New Delhi, India, 2015.

10. Inoplex. Electricity Generation from Biogas. Available online: https://www.inoplex.com.au/biogas/biogas-electric-generator (accessed on 2 November 2021).

11. Peres, A.P.G.; Lunelli, B.H. Application of biomass to hydrogen and syngas production. Chem. Eng. Trans. 2013, 32, 589-594. [CrossRef]

12. ENERGY.gov. Thermochemical Conversion Processes. Available online: www.energy.gov/eere/bioenergy/thermochemicalconversion-processes (accessed on 12 July 2021).

13. Miao, C.; Teng, K.; Wang, Y.; Jiang, L. Technoeconomic Analysis on a Hybrid Power System for the UK Household Using Renewable Energy: A Case Study. Energies 2020, 13, 3231. [CrossRef]

14. Singh, S.; Kaushik, S.C. Optimal sizing of grid integrated hybrid PV-biomass energy system using artificial bee colony algorithm. IET Renew. Power Gener. 2016, 10, 642-650. [CrossRef]

15. Malik, P.; Awasthi, M.; Sinha, S. Study of grid integrated biomass-based hybrid renewable energy systems for Himalayan terrain. Int. J. Sustain. Energy Plan. Manag. 2020, 28, 71-88.

16. Alturki, F.A.; Awwad, E.M. Sizing and cost minimization of standalone hybrid wt/pv/biomass/pump-hydro storage-based energy systems. Energies 2021, 14, 489. [CrossRef]

17. González, A.; Riba, J.-R.; Rius, A. Optimal sizing of a hybrid grid-connected photovoltaic-wind-biomass power system. Sustainability 2015, 7, 12787-12806. [CrossRef]

18. Al-Masri, H.M.; Magableh, S.K.; Abuelrub, A.; Alzaareer, K. Realistic coordination and sizing of a solar array combined with pumped hydro storage system. J. Energy Storage 2021, 41, 102915. [CrossRef]

19. Al-Masri, H.M.; Al-Sharqi, A.A. Technical design and optimal energy management of a hybrid photovoltaic biogas energy system using multi-objective grey wolf optimisation. IET Renew. Power Gener. 2020, 14, 2765-2778. [CrossRef]

20. Sinan Hasanoglu, M.; Dolen, M. Multi-objective feasibility enhanced particle swarm optimization. Eng. Optim. 2018, 50, 2013-2037. [CrossRef]

21. Royal Scientific Society (RSS). Available online: http://www.rss.jo/ (accessed on 27 August 2021).

22. NEPCO. Available online: https:/ / www.nepco.com.jo/en/Default_en.aspx (accessed on 13 June 2021).

23. Available online: https://portal.jordan.gov.jo/wps/portal/Home\#/ (accessed on 27 August 2021).

24. Municipality, G.A. Greater Amman Municipality (GAM) Ghabawi Municipal Solid Waste Landfill Stakeholder Engagement PlAN. Report version 2, Amman, Jordan, July 2019. Available online: https://www.amman.jo/site_doc/gen2.pdf (accessed on 3 January 2022).

25. Daily Amounts of Solid Municipal Wastes. Available online: http:/ /www.mma.gov.jo/Default.aspx (accessed on 4 November 2020).

26. Cerofolini, G.; Polignano, M. Generation-recombination phenomena in almost ideal silicon p-n junctions. J. Appl. Phys. 1988, 64, 6349-6356. [CrossRef]

27. Hegedus, S.S.; Luque, A. Status, trends, challenges and the bright future of solar electricity from photovoltaics. In Handbook of Photovoltaic Science and Engineering, 1st ed.; John Wiley \& Sons: Chichester, UK; Hoboken, NJ, USA, 2003; pp. 1-43.

28. Diaf, S.; Diaf, D.; Belhamel, M.; Haddadi, M.; Louche, A. A methodology for optimal sizing of autonomous hybrid PV/wind system. Energy Policy 2007, 35, 5708-5718. [CrossRef]

29. Ekren, O.; Ekren, B.Y. Size optimization of a PV/wind hybrid energy conversion system with battery storage using simulated annealing. Appl. Energy 2010, 87, 592-598. [CrossRef]

30. Roy, P.; Majumder, A.; Chakraborty, N. Optimization of a stand-alone Solar PV-Wind-DG Hybrid System for Distributed Power Generation at Sagar Island. AIP Conf. Proc. 2010, 1298, 260-265.

31. Ekren, O.; Ekren, B.Y. Size optimization of a PV/wind hybrid energy conversion system with battery storage using response surface methodology. Appl. Energy 2008, 85, 1086-1101. [CrossRef]

32. Eteiba, M.; Barakat, S.; Samy, M.; Wahba, W.I. Optimization of an off-grid PV/Biomass hybrid system with different battery technologies. Sustain. Cities Soc. 2018, 40, 713-727. [CrossRef]

33. Tsai, H.-L.; Tu, C.-S.; Su, Y.-J. Development of generalized photovoltaic model using MATLAB/SIMULINK. In Proceedings of the World Congress on Engineering and Computer Science, San Francisco, CA, USA, 22-24 October 2008; pp. 1-6.

34. Attivissimo, F.; Adamo, F.; Carullo, A.; Lanzolla, A.M.L.; Spertino, F.; Vallan, A. On the performance of the double-diode model in estimating the maximum power point for different photovoltaic technologies. Measurement 2013, 46, 3549-3559. [CrossRef]

35. Ishaque, K.; Salam, Z.; Taheri, H. Simple, fast and accurate two-diode model for photovoltaic modules. Sol. Energy Mater. Sol. Cells 2011, 95, 586-594. [CrossRef]

36. Al-Masri, H.M.; Magableh, S.K.; Abuelrub, A. Output power computation and sizing of a photovoltaic array by advanced modeling. Sustain. Energy Technol. Assess. 2021, 47, 101519. [CrossRef]

37. Ishaque, K.; Salam, Z.; Taheri, H. Accurate MATLAB simulink PV system simulator based on a two-diode model. J. Power Electron. 2011, 11, 179-187. [CrossRef] 
38. Ramos Hernanz, J.; Campayo Martin, J.; Zamora Belver, I.; Larranaga Lesaka, J.; Zulueta Guerrero, E.; Puelles Perez, E. Modelling of photovoltaic module. In Proceedings of the International Conference on Renewable Energies and Power Quality (ICREPQ'10), Granada, Spain, 23-25 March 2010.

39. Al-Masri, H.M.; Magableh, S.K.; Abuelrub, A.; Saadeh, O.; Ehsani, M. Impact of Different Photovoltaic Models on the Design of a Combined Solar Array and Pumped Hydro Storage System. Appl. Sci. 2020, 10, 3650. [CrossRef]

40. Chin, V.J.; Salam, Z.; Ishaque, K. An accurate modelling of the two-diode model of PV module using a hybrid solution based on differential evolution. Energy Convers. Manag. 2016, 124, 42-50. [CrossRef]

41. Ma, T.; Yang, H.; Lu, L.; Peng, J. Pumped storage-based standalone photovoltaic power generation system: Modeling and techno-economic optimization. Appl. Energy 2015, 137, 649-659. [CrossRef]

42. Orioli, A.; Di Gangi, A. A procedure to evaluate the seven parameters of the two-diode model for photovoltaic modules. Renew. Energy 2019, 139, 582-599. [CrossRef]

43. Gupta, A.; Saini, R.; Sharma, M. Steady-state modelling of hybrid energy system for off grid electrification of cluster of villages. Renew. Energy 2010, 35, 520-535. [CrossRef]

44. Xu, L.; Ruan, X.; Mao, C.; Zhang, B.; Luo, Y. An improved optimal sizing method for wind-solar-battery hybrid power system. IEEE Trans. Sustain. Energy 2013, 4, 774-785.

45. Diaf, S.; Notton, G.; Belhamel, M.; Haddadi, M.; Louche, A. Design and techno-economical optimization for hybrid PV/wind system under various meteorological conditions. Appl. Energy 2008, 85, 968-987. [CrossRef]

46. Al-Shaalan, A.M. Reliability Evaluation of Power Systems. In Reliability and Maintenance-an Overview of Cases; Kounis, L.D., Ed.; IntechOpen: London, UK, 2018; pp. 1-25.

47. Tian, Z.; Seifi, A.A. Reliability analysis of hybrid energy system. Int. J. Reliab. Qual. Saf. Eng. 2014, 21, 1450011. [CrossRef]

48. Ai, B.; Yang, H.; Shen, H.; Liao, X. Computer-aided design of PV/wind hybrid system. Renew. Energy 2003, $28,1491-1512$. [CrossRef]

49. Upadhyay, S.; Sharma, M. Development of hybrid energy system with cycle charging strategy using particle swarm optimization for a remote area in India. Renew. Energy 2015, 77, 586-598. [CrossRef]

50. Arabali, A.; Ghofrani, M.; Etezadi-Amoli, M.; Fadali, M.S. Stochastic performance assessment and sizing for a hybrid power system of solar/wind/energy storage. IEEE Trans. Sustain. Energy 2013, 5, 363-371. [CrossRef]

51. Environment, M.O. Jordan's Third National Communication on Climate Change; Ministry of Environment: Amman, Jordan, 2014; pp. 1-281. Available online: https://unfccc.int/resource/docs/natc/jornc3.pdf (accessed on 3 January 2022).

52. Bank, A.D. Guidelines for Estimating Greenhouse Gas Emissions of Asian Development Bank Projects: Additional Guidance for Clean Energy Projects; Asian Development Bank: Manila, Philippines, 2017.

53. Stages, L.C. Life Cycle Greenhouse Gas Emissions from Solar Photovoltaics. 2012. Available online: https://www.nrel.gov/docs/ fy13osti/56487.pdf (accessed on 3 January 2022).

54. Amponsah, N.Y.; Troldborg, M.; Kington, B.; Aalders, I.; Hough, R.L. Greenhouse gas emissions from renewable energy sources: A review of lifecycle considerations. Renew. Sustain. Energy Rev. 2014, 39, 461-475. [CrossRef]

55. Zhou, Y.; Swidler, D.; Searle, S.; Baldino, C. Life-Cycle Greenhouse Gas Emissions of Biomethane and Hydrogen Pathways in The European Union. In The International Council of Clean Transportation; 2021, pp. 27-36. Available online: https://www.h2 knowledgecentre.com/content/policypaper2554 (accessed on 3 January 2022).

56. Pohekar, S.D.; Ramachandran, M. Application of multi-criteria decision making to sustainable energy planning-A review. Renew. Sustain. Energy Rev. 2004, 8, 365-381. [CrossRef]

57. Ho, W.; Xu, X.; Dey, P.K. Multi-criteria decision making approaches for supplier evaluation and selection: A literature review. Eur. J. Oper. Res. 2010, 202, 16-24. [CrossRef]

58. Hasanoglu, M.S.; Dolen, M. Feasibility enhanced particle swarm optimization for constrained mechanical design problems. Proc. Inst. Mech. Eng. Part C J. Mech. Eng. Sci. 2018, 232, 381-400. [CrossRef]

59. Hasanoğlu, M.S. An Advanced evolutionary programming method for mechanical system design: Feasibility enhanced particle swarm optimization. Ph.D. Thesis, Middle East Technical University, Ankara, Turkey, 2019; pp. 9-61. Available online: http:/ / etd.lib.metu.edu.tr/upload/12623027/index.pdf (accessed on 3 January 2022).

60. Kalesar, B.M.; Rouhollahi, B.; Noshahr, J.B.; Tadayon, M.; Kermani, M. Multi-Objective Fuzzy Model for Optimal Siting and Sizing of DG Units to Reduce Losses Using Genetic Algorithm. In Proceedings of the 2018 IEEE International Conference on Environment and Electrical Engineering and 2018 IEEE Industrial and Commercial Power Systems Europe (EEEIC/I\&CPS Europe), Palermo, Italy, 12-15 June 2018; pp. 1-6.

61. Alomoush, M.I. Microgrid combined power-heat economic-emission dispatch considering stochastic renewable energy resources, power purchase and emission tax. Energy Convers. Manag. 2019, 200, 112090. [CrossRef] 